\title{
Symbolism of clothing: The relationship between teacher clothing and children's perceptions in primary school physical education
}

\author{
Brent Bradford \\ Concordia University of Edmonton \\ brent.bradford@concordia.ab.ca
}

\section{Clive Hickson}

University of Alberta

clive.hickson@ualberta.ca

Keywords: physical education, elementary school children, teacher clothing, symbolism, role modeling, perceived teaching effectiveness

\begin{abstract}
Teachers of physical education (PE) have the responsibility to develop and teach programs that physically educate primary school children. How teachers achieve this aim is a critical consideration. Issues such as planning, delivery, and evaluation are constant themes of consideration; however, other areas of preparedness such as personal presentation are not often investigated. The purpose of this research study was to determine whether a primary school teacher's choice of clothing in PE impacted children's perceptions toward that teacher and the PE lesson. Primary school-aged children from six northern Alberta, Canada schools participated in the study. Quantitative data was collected through the use of a specificallydesigned Mannequin Clothing Assessment Questionnaire (MCAQ); while focus group interviews were employed to collect qualitative data. Both quantitative and qualitative data illustrated that teacher clothing is perceived by children to be important in PE lessons. Running shoes, athletic-style pants, and a golf shirt were perceived to be the most effective clothing choices for the ability to demonstrate, role modeling, safety, comfort, and mobility when teaching PE. This information may prove to be beneficial to the literature on effective teaching, teacher as a role model, and the symbolism of teacher clothing.
\end{abstract}

\section{Introduction}

Primary school physical education (PE) programs should provide breadth, variety, and educational experiences that help develop the whole child (Hickson, 2003). As each subject area can contribute unique strengths to educational programs, all subject areas must be taught effectively. In particular, research indicates that PE can positively affect child development (Fishburne, 2005; Pangrazi \& Beighle, 2010; Physical and Health Education Canada, 2016). Children experience several benefits from quality PE programs such as: higher levels of selfefficacy; greater academic performance; less disruptive behaviour; less anxiety (Medina, 2008); improved physical skills (Rink, 2004; 2003); health benefits (Dauenhauer \& Keating, 2011); and leadership opportunities (Lieberman, Arndt, \& Daggett, 2007; Martinek \& Schilling, 2003).

In light of this understanding, it is essential that children are exposed to PE environments that promote teaching and learning (Hickson, 2003). Such environments would consist of wellplanned lessons with effective lesson delivery (Fishburne, 2005; Rink, 2006), proper assessment techniques (Metzler, 2005; Pangrazi \& Beighle, 2010), and developmentally appropriate activities (Fishburne, 2005; Gleddie, Hickson, \& Bradford, in press). PE environments that 
promote learning such as providing opportunities to acquire knowledge, skills, and attitudes to choose healthy active lifestyles are often referred to as 'quality learning' environments (Cherubini, 2009; Hickson, 2003).

In order for teachers of PE to develop quality learning environments, various teaching considerations are required. Although issues such as planning (Fishburne, 2005; LaBillois \& Lagacé-Séguin, 2010), lesson delivery (Bradford \& Hickson, 2014; Fishburne, 2005), and evaluation of learning (Metzler, 2005; Pangrazi \& Beighle, 2010) are constant themes of consideration, other areas of preparedness such as personal presentation have received little investigation. As the role modeling of teachers (for example, behaviours, actions, appearance) can stimulate child development (Arthur, 2011), what a primary school teacher chooses to wear whilst teaching PE may be perceived by children as part of a teacher's role modeling.

\section{Literature review}

\section{Effective teaching in PE}

Teacher effectiveness occurs when intended learning outcomes are achieved (Rink, 2003; Yilmaz, 2011). Teachers of PE are effective when they are well organised; have established routines; manage learning environments; follow developmentally appropriate programs; and assess for learning (Rink \& Hall, 2008). Effective teaching of PE results in the development of knowledge, skills, and attitudes to live healthy active lifestyles (Gleddie et al., in press; Pangrazi \& Beighle, 2013).

\section{Teacher as a role model in PE}

Social cognitive theory (Bandura, 1986) is a framework for understanding, predicting, and changing human behaviour (Hall, 2012). Bandura (1986) contended that human behaviour is a complex interaction involving personal factors, the environment, and behaviour. From this theoretical perspective, it is evident that both teachers and their students are influenced by the interplay of behavioural, personal, and environmental influences. Hall (2012) suggested that there is consensus among investigators that the validity of social cognitive theory is strong and that it has been used and successfully applied in the PE domain. Therefore, stemming from Bandura's (1986) social cognitive theory, role modeling is a fundamental mode of communication for teaching and learning (Cardinal, 2001). Enthusiastic teachers toward children's learning create positive learning environments, and are commonly defined by the use of eye contact, facial expression, vocalisation, gesturing and movement throughout the learning environment (Vidourek, King, Bernard, Murnan, \& Nabors, 2011).

Teacher actions seem to be as important as the material being presented (Pangrazi \& Beighle, 2010). In light of this understanding, teachers of PE naturally become role models for children (Whitley, Sage, \& Butcher, 1988). Although attitudes and actions are often considered when discussing role modeling, the symbolism of clothing has not received great attention in PE. Therefore, the issue of teacher clothing and its influence on children's perceptions of the teacher is worthy of consideration.

\section{Symbolism of teacher clothing in PE}

What a person chooses to wear is a powerful communicator (Damhorst, Miller-Spillman, \& Michelman, 2005; Roach, 1997). Whether accurate or not, perceptions about a person based on clothing serve as a source of information (Molloy, 1975; Roach, 1997). Although there 
is research indicating the effect of school uniform on student activity choice (for example, Norrish, Farringdon, Bulsara, \& Hands, 2012), minimal research has considered teacher clothing in PE. A teacher's appearance is essentially a non-verbal form of communication which influences the validity of verbal communication (Underwood, Kenner, \& McCune, 2002). Therefore, teachers should consider their clothing choice to gain a level of respect (Freeburg \& Workman, 2010). Even if a teacher's clothing is not intended to communicate, its interpretation as a function of individual choice give it communicative relevance (Hickson \& Stacks, 1993).

In PE, where effective teachers teach by moving (Metzler, 2005; Rink \& Hall, 2008), teacher clothing must support the learning environment. Teachers often face challenges on a daily basis to ensure that they are being effective in the delivery of their lessons (Roach, 1997). Therefore, it is logical for them to obtain every technique, advantage, and situational control method that may enhance their teaching effectiveness. Hence, teacher clothing may influence children's affect for the teacher, student mood, and perceptions that learning activities are important (Hickson \& Bradford, 2012; Roach, 1997).

\section{Perception formation toward teachers of PE}

Our environmental conception is created on sensory perception (Huumo, 2010). Perception is to inform us about the objects and events in our immediate environment that can intelligently guide our behaviour (Blake \& Sekuler, 2006). Every activity (for example, reading, eating, talking, exercising) is strongly influenced by what one sees, hears, feels, touches, smells, and tastes (Blake \& Sekuler, 2006), and forming a perception involves all human senses (Rock, 1983; Rookes \& Willson, 2000). This notion provides a strong argument for the knowledge of whether a teacher's choice of clothing can impact children's perceptions toward that teacher.

This study, therefore, was guided by two questions: What is the nature of the relationship between the PE teacher as a role model and the symbolism of clothing? and How are children's perceptions toward the PE teacher influenced by the teacher's choice of clothing in PE lessons?

\section{Methodology}

\section{Ethical considerations}

The research study was conducted as approved by the University Research Ethics Board at University of Alberta in Canada. The main ethical considerations were participants' informed consent, confidentiality, and anonymity.

Specifically, discussions were held at the school district level to identify possible schools and gain consent to approach school administration. After gaining this consent, school principal permission was obtained to approach staff members and students concerning their possible participation in the study. Teachers that expressed a willingness to have their students participate in the study facilitated the distribution of an information letter and consent form to the homes of their students. The information letter outlined the study's purpose and procedures, participant obligations and responsibilities, confidentiality, and the right for withdrawal at any time without penalty or prejudice. Only the students with signed consent forms participated in the study.

Consent forms and all other data documents were kept in a confidential and secure manner as per University Research Ethics Board policies. Names of participants were not placed on any data gathering documents. When necessary, documents were assigned a number in order to record any difference of opinion and thought between participants. At all times, care was taken to ensure that all participants were treated in a manner that was respectful of their rights and personal dignity. 


\section{Phase 1: Quantitative phase}

Data were obtained from 389 children ranging from Grade 1 through to Grade 6 at six primary schools in northern Alberta, Canada through the use of a Mannequin Clothing Assessment Questionnaire (MCAQ). As this questionnaire was specifically created for this research, a pilot study was conducted to ensure that it could be used appropriately with primary school children. The MCAQ included 28 mannequin images depicting teachers wearing different clothing (see Appendix $A$ for a list of clothing combinations on the MCAQ). Participants were asked if they perceived the teacher to be a 'really good,' 'good,' 'okay,' 'not so good,' or 'really not good' teacher of PE (see Figure 1). With each mannequin, participants were able to write why they chose their response.

Figure 1. MCAQ summative response scale

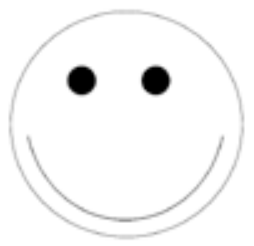

REALLY GOOD

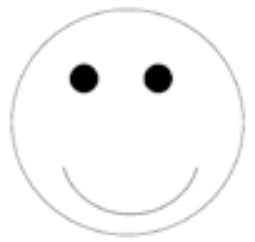

GOOD

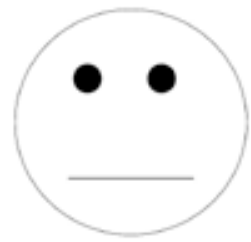

OKAY

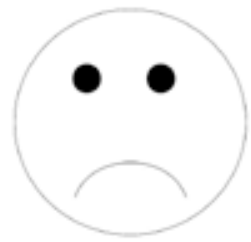

NOT SO GOOD

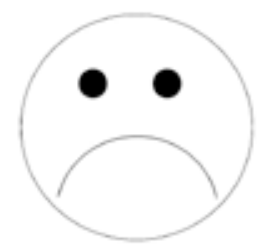

REALLY NOT GOOD

Descriptive statistics were employed to identify general trends and createa depth of understanding. Inferences were made regarding mean differences and order of descending means related to each mannequin. Participant comments provided a limited amount of qualitative data, which were utilised to help develop questions for Phase 2.

\section{Phase 2: Qualitative phase}

Focus group interviews (FGIs) were conducted with a total of 19 students at two Phase 1 schools. At each school, three FGls were conducted in groupings of Grades 1 and 2, 3 and 4, as well as 5 and 6 students. The grade-level groupings were chosen to align with developmental levels of child development (Fishburne, 2005), thereby creating a conducive discussion-based environment. An FGI Protocol was developed to discuss the trends identified from the MCAQ data and to address the research question.

Participants responded to open-ended questions and drew a teacher of PE. Drawings helped generate further discussion and clarification. FGls were recorded and transcribed for content analysis. NVivo 10 data management computer program software was used to identify common terms and statements, while the coding categorisation process was conducted by the researcher and an assistant. Constant comparative analysis was used (Creswell, 2012; Mertens, 2014) to assist in the development of categories and sub-categories and emerging themes were then identified and used to organise the data and identify findings (David \& Sutton, 2004).

\section{Results and discussion}

\section{Phase 1: MCAQ analysis}

Participants rated each mannequin according to clothing and perceived capability to teach $P E$. After calculating the means from the summative response scale, the 28 mannequins were ordered by descending means (see Table1). Notably, the highest 16 means were mannequins 
wearing 'running shoes' $(\mathrm{M}=4.24-2.87)$ and the lowest 12 were mannequins wearing 'dress shoes' $(M=2.86-1.68)$. With regard to lower body clothing, mannequins wearing 'sweat pants' or 'khaki pants' received higher means $(M=4.24-3.73)$ than mannequins wearing 'dress pants' and 'skirts' $(M=3.69-2.87)$. Further, mannequins wearing running shoes with sweat pants or khaki pants received means ranging from 4.24 to 3.73. Additionally, mannequins wearing dress shoes with sweat pants or khaki pants received means ranging from 2.86 to 2.42. Whereas, mannequins wearing dress shoes with dress pants received the lowest means ranging from 2.41 to 1.68 . With upper body clothing, mannequins wearing 'golf shirts' received the highest means. Also, similar to the lower body clothing, mannequins wearing running shoes with sweat pants or khaki pants received higher means when also wearing golf shirts.

Table 1. Mannequins* in order of descending means
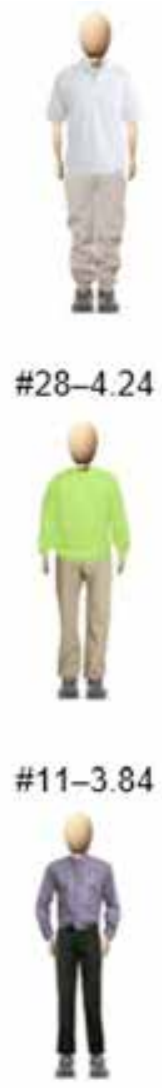

\#2-2.98
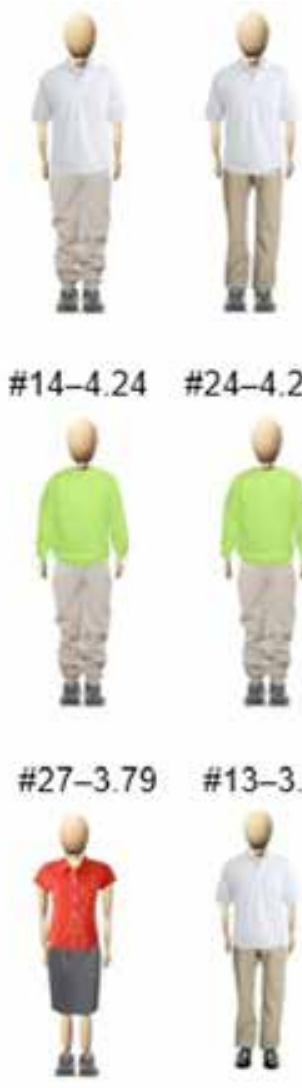

\#16-2.87
\#24-4.22 \#1
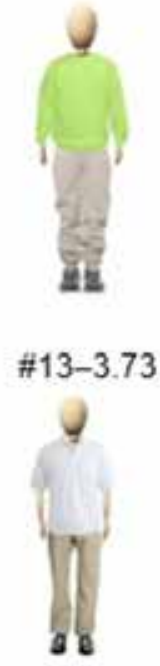

\#9-2.86
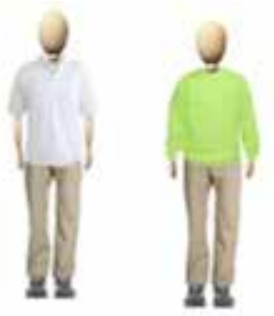

\#10-4.18 \#26-3.98
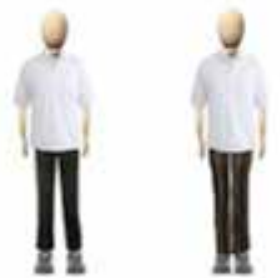

\#4-3.69
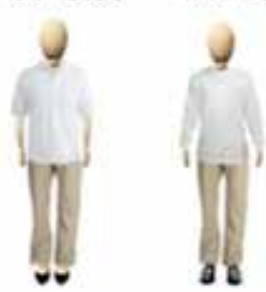

\#23-2.63

$\# 22-2.42$

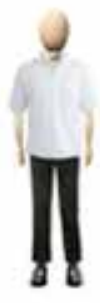

$\# 3-2.41$

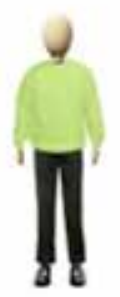

\#6-2.18
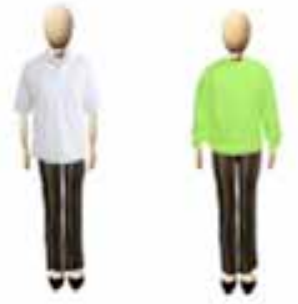

$\# 18-2.13 \# 19-2.03$
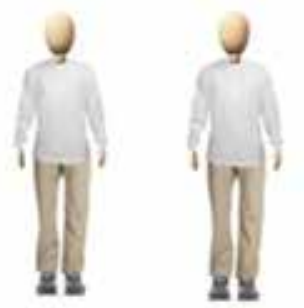

$\# 21-3.89$

\#8-3.87
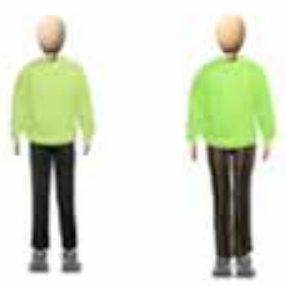

\#5-3.41

\#20-3.39
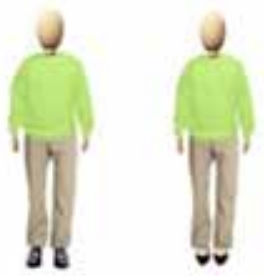

\#12-2.60

$\# 25-2.47$
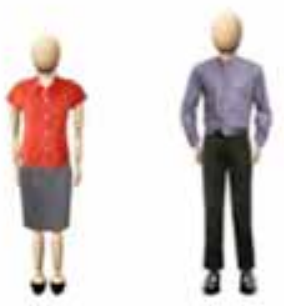

\#15-1.82

$\# 1-1.68$

\footnotetext{
* mannequins \#1-14 depict male teachers of PE
}

* mannequins \#15-28 depict female teachers of PE 
The participants identified that the most appropriate clothing choices for teaching PE were running shoes, sweat pants or khaki pants, and golf shirts. Conversely, dress shoes were perceived to be the least appropriate clothing choice. This was further supported by participants who chose to write comments on their MCAQ. Although comments were not extensive, five particular themes were identified and supported through such comments as:

- Ability to Demonstrate: "He won't show you exactly what he wants you to do," and "Then the teacher can move around and they can help you more."

- Comfort: "He will be sweating," and "I like the t-shirt because she could start to sweat."

- Mobility: "You can't run in the dress shirt and dress pants," and "You can move around better in khaki pants than in a skirt."

- Role Modeling: "I feel that she doesn't want to teach gym," and "This is the kind of teacher I want teaching me in gym class."

- Safety: "He will fall and choke," and "Slip or fall in high-heels."

\section{Phase 2: Focus Group Interviews (FGIs)}

With support from Table 1 and participant comments on the MCAQ, questions for FGls were established and a coding tree was developed during the analysis stage. Findings from participant perceptions were identified and categorised in order to answer the research question.

The data suggested that the relationship is multifaceted and extensive. Support of a relationship existing between teacher as a role model and the symbolism of clothing was found in participant comments. For example, a Grade 4 female stated, "I think gym teachers are supposed to be a role model because if you're going to be a gym teacher, you're supposed to show them how to do it..., and if you're not showing them what to do, what are they going to learn?" Comments such as "He can't be a good role model because he looks like he is going to a wedding.", "He is dressed like a waitress.", and "Looks really unready!" further illustrated the role model theme. Whereas, contrary comments included "This is the kind of teacher I want teaching me in gym class.”, "Really Ready!”, and “...because it's proper gym clothing."

When explaining the existence of a relationship between teachers as role models and teacher clothing, a Grade 6 male rated Mannequin 1 by stating, “... really not good, because he's wearing like a dress shirt and tie, dress pants and dress shoes, ... it looks like he's going to a party ..." In a similar manner, a Grade 5 male stated Mannequin 1 is, "... wearing dress stuff and it's mainly meant for like going out to like a party or something." He added, "So, you're not really active, you're just like, like standing around talking and stuff." While supporting his perceptions toward Mannequin 1, he then added, "....He could sit on the sidelines pretty easily because you're not prepared for like teaching kids what they're supposed to do."

Participant drawings of teachers of PE helped to further attest to a relationship between teachers as role models and the symbolism of teacher clothing. For example, participants referred to the importance of role modeling when explaining their drawings. A Grade 1 female referred to her teacher as a role model in relation to clothing choices by stating, "I drew all the stuff that you should be wearing ... running shoes, a t-shirt and shorts." 
Figure 2. Participant drawing of a teacher of $P E$

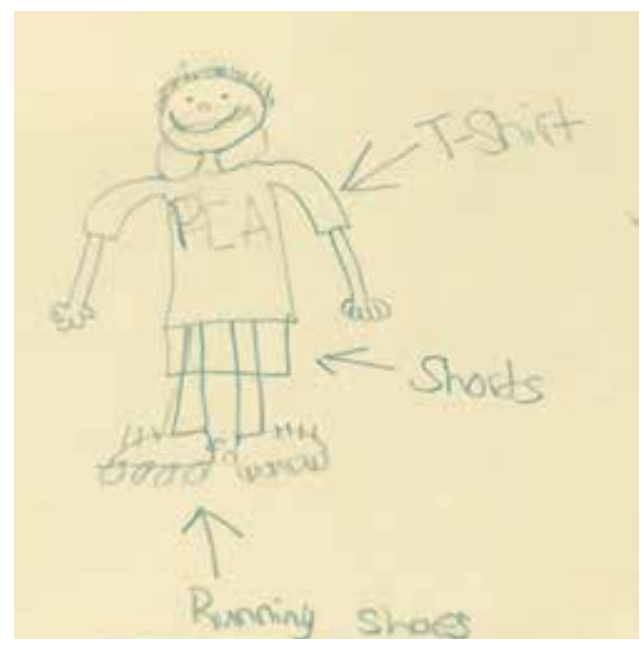

Figure 3. Participant Drawing of a teacher of $P E$

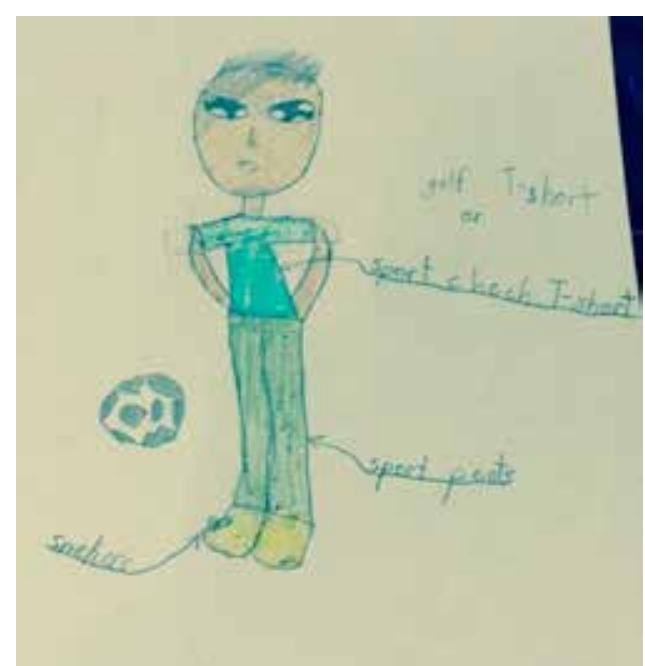

The findings from the MCAQ and FGls suggested that teachers of PE must view themselves as role models. This finding supports the work of Dean, Adams, and Comeau (2005) who stated that role modeling is an important issue for those teaching PE, and the findings support the literature that states that positive, competent modeling by teachers has a significant impact on school children. The impact on the learning environment when teachers of PE are perceived as role models was illustrated by participant comments such as:

- Perceptions toward the Teacher. "He wouldn't run fast with dress shoes,", "He can't really run in the shoes,", "Golf shirt would be easy to move your arms,", and "He can have more mobility with a golf shirt."

Professional attire enhances attributes of teachers (Gordon, 2010). This was evident when participants perceived teachers wearing inappropriate clothing to lack caring toward the teaching of PE. For example:

- Perceptions toward PE. "Then the teacher could teach me better,", "Because if he's not comfortable, he might make mistakes ... on the stuff that he's teaching us,", "... because if they can't move, then you won't be able to learn,", and while referring to an ineffective PE learning environment, a Grade 6 male stated, "We had a substitute. And that day she came in, she had her dress on and stuff, and she just said "go play with the basketballs," and she sat on the bench and watched us."

\section{The importance of teacher clothing choice}

It is clear that a relationship exists between the teacher as a role model and the symbolism of clothing, and children's perceptions toward the teacher and PE are influenced by teacher choice of clothing. Participants consistently pointed toward the importance of wearing running shoes, sweat pants/khaki pants/shorts with a golf shirt; a teacher that is mobile, comfortable, and able to demonstrate in the learning environment.

This lends itself to the literature. In order to demonstrate motor skills, teachers must consider the appropriateness of their clothing for physical activity (Fishburne, 2005), and when teachers of PE demonstrate motor skills and display enthusiasm throughout lessons, they 
can help children reach higher levels of motivation (Vidourek et al., 2011). Similarly, Workman and Freeburg (2009) contended that wearing appropriate clothing is a sign of responding to situational demands. The data does indicate that clothing choice must be part of a teacher's repertoire.

\section{The impact of teacher clothing on the learning environment}

This study has helped develop a deeper understanding of how teacher clothing choice in PE can impact children's perceptions toward the quality of learning experiences. With regard to the type of clothing being worn, a Grade 1 female explained that a teacher would likely be a 'not so good' teacher of PE, "Because if he's not comfortable, he might make mistakes on the stuff that he's teaching us." Statements such as this indicate that clothing choice can impact how children perceive the learning environment.

Clothing choices such as, running shoes, sweat pants and a golf shirt were perceived as being appropriate clothing for a teacher of PE to be wearing. Although practicality of clothing choice is important (Roach, 1997), participants also identified such qualities as caring for the subject area, ready to teach, and able to participate. Whereas teachers, when wearing inappropriate clothing such as dress shoes, dress pants, and a dress shirt, were perceived as being unable to demonstrate skills (for example, jumping), unsafe, and not caring about the subject area.

In light of this, teachers of PE need to understand that if they wish to create a learning environment that children perceive as supporting their learning, they need to wear clothing that is appropriate for physical activity. The demonstration of movement skills is critical for a teacher of PE, which is reiterated through participant data. When discussing Mannequin 1, a Grade 6 female wrote, "They won't be able to show you how to do it." If a teacher is unable to demonstrate the skills being learned by children, the learning experiences will not be as effective as compared to a teacher who is able to demonstrate. Teacher clothing has been identified, through this study, as a major reason for being able or unable to demonstrate skills in PE which can be tied to role modeling.

It is important to recognise that primary school teachers, including relief teachers, may not have time to always change into clothing such as sweat pants or a golf shirt during their school day. For example, teachers not only are responsible for their teaching, but are also involved in extracurricular programming and activities, formal and informal meetings with parents, teachers, and students, and many other school-related responsibilities. This results in little 'down time' for teachers. However, the data has indicated that the simple change of dress shoes into running shoes can positively influence the perceptions of the children toward the teacher, the subject area, and the learning environment. Research endeavours regarding PE that have considered effective learning environments have focused on issues such as planning, assessment, and delivery methods (Metzler, 2005; Rink \& Hall, 2008). However, in this study, participants consistently communicated that teacher clothing can assist in the effectiveness of PE teaching.

\section{Teacher credibility as perceived by children}

The data indicated that the participants perceived the clothing worn by teachers of PE as important and adds to the research conducted by Hickson and Bradford (2012). Participant comments indicated that the credibility of the teacher is questioned. For example, when referring to Mannequin 15, a Grade 6 male stated, "This shows that the teacher does not care...", while a Grade 4 male contended, "It's looks like she's going to a wedding." 
What a teacher chooses to wear whilst teaching PE is a powerful communicator to the children (Damhorst et al., 2005). If a teacher is preparing to teach PE wearing inappropriate clothing, a non-verbal message is being sent to the children that the teacher may not care for PE and may not be able to teach the skills that are to be learned. When this occurs, the teacher is communicating to the children that PE is simply a time for 'not learning.' This finding adds to the 'busy, happy, good' literature of Placek (1983) and Hickson and Fishburne (2005).

Limitations of this study included: the inability to acknowledge and/or measure all potential variables (for example, participants' background knowledge); the limited number of school sites; the lack of randomisation; and the inability to include all potential clothing items and colours on the MCAQ.

\section{Synthesis}

Although it has been noted that teachers of PE have the responsibility to develop and teach programs that physically educate children (Hickson \& Fishburne, 2005), the findings from this study may have added to the PE research literature concerning effective teaching, teacher as a role model, and the symbolism of teacher clothing. As previously stated, issues such as planning, lesson delivery (Bradford \& Hickson, 2014; Mawer, 1995; Rink, 2006), and the evaluation of learning (Metzler, 2005; Pangrazi \& Beighle, 2010) have been constant themes of consideration and thought, but an area of teacher preparedness such as teacher clothing has not been investigated to the same degree (Hickson \& Bradford, 2012). This study provided another thought for teachers when considering their practice and, specifically, their clothing choice.

This study helped develop the understanding of teacher clothing. Although a teacher of PE can prepare by developing thorough lesson plans and effective assessment techniques (Metzler, 2005; Pangrazi \& Beighle, 2010), if that teacher chooses to wear inappropriate clothing while teaching, the teacher may well be perceived as being not skilful, uncaring, and unsafe toward the subject area. If teachers wish to create conducive learning environments, they must consider more than planning and assessment. The importance of demonstrating and role modeling has been supported throughout the literature. The demonstration of fundamental movement skills has been perceived to be one of the most powerful forms of communicating to children in PE (Bradford, Hickson, \& Evaniew, 2014; Volger, 2003). Wearing appropriate clothing to be able to do so, therefore, is critical.

In light of this information, teachers should find ways and the time to ensure that they wear appropriate clothing when teaching PE. After all, if teacher clothing choices can assist in children's learning, does it not seem worth the effort?

\section{Summary, conclusions and implications}

Providing conducive learning environments is a critical aim for all teachers. The findings from this study present a number of points that either confirm the research literature or are worthy of consideration for further research. A relationship was found between teacher clothing in PE and participant perceptions toward the teacher and PE. Hence, this information of the impact that clothing can have on a child's perception of a PE teacher should be disseminated widely across the school system. Such discussion could be incorporated into effective teaching understanding. For example, teachers need to understand the importance their choice of clothing has on the impact of their PE program. With school administrative support, discussing strategies for finding the time to change into appropriate clothing for PE classes during the school day would start this important conversation. It is also apparent that the participants 
held strong views about clothing being worn by teachers of PE. Therefore, it is suggested that teachers listen to the voices of those children that they teach. Encouraging children to share their thoughts would enable teachers to gather valuable information as to what impacts a child's learning and influences their choice of engaging in lifelong physical activity.

Although trends were found for primary school children's perceptions toward teacher clothing in PE, it must be noted that this study appears to be the first of its kind. The review of related literature found no other work that has explored whether or not teacher clothing impacts children's perceptions in PE. Therefore, ideas, implications, and future research questions must be shared for future thoughts and discussion. It is important that we continue to investigate the different variables that can impact PE teaching and learning. This is important in order to ensure that children are provided with conducive PE learning experiences.

Conducting future research to further investigate these findings may serve to create a better and more thorough understanding of the behavioural, personal, and environmental factors (Bandura, 1986) that can influence effective teaching of PE. Although this study identified some important findings, these findings are only the beginning of our understanding of teacher clothing and how it impacts school children's perceptions towards their teachers and PE. 


\section{References}

Arthur, J. (2011). Personal character and tomorrow's citizens: Students expectations of their teachers. International Journal of Educational Research, 50, 184-189.

Bandura, A. (1986). Social foundations of thought and action. Englewood Cliffs, NJ: Prentice Hall.

Berg, B. (2009). Qualitative research methods for the social sciences. ( $7^{\text {th }}$ Ed.). Toronto, ON: Allyn \& Bacon.

Blake, R., \& Sekuler, R. (2006). Perception. (5 $5^{\text {th }}$ Ed.). New York, NY: McGraw-Hill.

Bogdan, R., \& Biklen, S. (1992). Qualitative research for education: An introduction to theory and methods. Boston: Allyn and Bacon.

Bradford, B. \& Hickson, C. (2014). Teaching Styles in Elementary School Physical Education: The Effect on Children's Learning. The International Journal of Pedagogy and Curriculum, 20(3), 1-17.

Bradford, B., Hickson, C., \& Evaniew, A. (2014). Role Modeling: The Forgotten Part of Elementary School Physical Education. Journal of Higher Education Theory and Practice, 14(5), 18-23.

Cardinal, B.J. (2001). Role modeling attitudes and physical activity and fitness promoting behaviors of HPERD professionals and preprofessionals. Research Quarterly for Exercise and Sport, 71(1), 84-90.

Cherubini, J. (2009). Positive psychology and quality physical education. Journal of Physical, Education, Recreation \& Dance, 80(7), 42-51.

Creswell, J.W. (2012). Educational research: Planning, conducting, and evaluating quantitative and qualitative research. ( $4^{\text {th }}$ Ed.). Boston, MA: Pearson.

Damhorst, M.L., Miller-Spillman, K.A., \& Michelman, S.O. (2005). The meanings of dress (2 ${ }^{\text {nd }}$ Ed.). New York, NY: Fairchild Publications, Inc.

Dauenhauer, B.D., \& Keating, X.D. (2011). The influence of physical education on physical activity levels of urban elementary students. Research Quarterly for Exercise and Sport, 82(3), 512-520.

David, M., \& Sutton, C.D. (2004). Social research: The basics. Thousand Oaks, CA: Sage Publications.

Dean, M.B., Adams, T.M., \& Comeau, M.J. (2005). The effect of a female physical educator's physical appearance on physical fitness knowledge and attitudes of junior high students. The Physical Educator, 62(1), 14-25.

Fishburne, G.J. (2005). Developmentally appropriate physical education for children and youth. University of Alberta: Ripon Publishing.

Freeburg, B.W., \& Workman, J.E. (2010). Media frames regarding teacher dress: Implications for career and technical education teacher preparation. Career and Technical Education Research, 35(1), $29-45$.

Gleddie, D.L., Hickson, C., \& Bradford, B. (in press). Physical Education for Elementary School Teachers: Developing Physical Literacy in Children. Victoria: Ripon Publishing.

Gordon, H.R.D. (2010). Career and technical education administrators' perceptions of secondary teachers' attire as indicated by selected professional attributes. Journal of Career and Technical Education, 25(1), 47-61.

Hall, N.D. (2012). The use of mental imagery by physical education teachers. (Unpublished doctoral dissertation). University of Alberta, Edmonton, Canada. Retrieved December 24, 2016 from https://era.library.ualberta.ca/files/2j62s591h/Hall_Nathan_Spring\%202012.pdf

Hickson, C. \& Bradford, B. (2012). What We Wear: Does It Matter? Proceedings. Hawaii International Conference on Education. Honolulu, Hawaii, USA. 
Hickson, C. (2003). Putting education back into P.E. International Journal of Learning. 10.

Hickson, C.N., \& Fishburne, G.J. (2005). Teacher development: Enhancing effective teaching in elementary school physical education. Research Quarterly for Exercise and Sport. 76(1), A77.

Hickson, M.L., \& Stacks, D.W. (1993). NVC: Nonverbal communication studies and applications. (3 ${ }^{\text {rd }}$ Ed.). Dubuque, IA: William C. Brown.

Huumo, T. (2010). Is perception a directional relationship? On directionality and its motivation in Finnish expressions on sensory perception. Linguistics, 48(1), 49-97.

LaBillois, J.M., \& Lagacé-Séguin, D.G. (2010). Does a good fit matter? Exploring teaching styles, emotion regulation, and child anxiety in the classroom. Early Childhood Developemt and Care, 179(3), 303-315.

Lieberman, L.J., Arndt, K., \& Daggett, S. (2007). Promoting leadership in physical education and recreation. Journal of Physical Education, Recreation \& Dance, 78(3), 46-50.

Martinek, T. \& Schilling, T. (2003). Developing compassionate leadership in underserved youths. Journal of Physical Education, Recreation \& Dance, 74(5), 33-39.

Mawer, M. (1995). The effective teaching of physical education. London: Longman.

Medina, J. (2008). Brain Rules. Seattle, WA: Pear Press.

Mertens, D. M. (2014). Research and evaluation in education and psychology. (4th Ed.). Thousand Oaks, CA: Sage Publications, Inc.

Metzler, M.W. (2005). Instructional models for physical education. (2 ${ }^{\text {nd }}$ Ed.). Scottsdale, AZ: Holcomb Hathaway Publishers.

Molloy, J.T. (1975). Dress for success. New York, NY: Peter H. Wyden Publisher.

Norrish, H., Farringdon, F., Bulsara, M., \& Hands, B. (2012). The effect of school uniform on incidental physical activity among 10-year-old children. Asia-Pacific Journal of Health, Sport and Physical Education, 3(1), 51-63.

Pangrazi, R.P. \& Beighle, A. (2010). Dynamic physical education for elementary school children. (16 $6^{\text {th }}$ Ed.). San Francisco, CA: Benjamin Cummings.

Pangrazi, R.P., \& Beighle, A. (2013). Dynamic physical education for elementary school children. $\left(17^{\text {th }}\right.$ Ed.). New York, NY: Pearson.

Physical \& Health Education (PHE) Canada. (2016). Our Vision \& Mission. Retrieved December 24, 2016 from http://www.phecanada.ca/about-us/vision/mission

Placek, J.H. (1983). Conceptions of success in teaching: Busy, happy, and good? In T. Templin and J. Olsen (Eds.). Teaching in physical education. (pp. 45-56). Illinois: Human Kinetics Publishers.

Rink, J.E. (2003). Effective instruction in physical education. In S. Silverman, \& C.D. Ennis (Eds.). Student learning in physical education: Applying research to enhance instruction $\left(2^{\text {nd }} \mathrm{Ed}\right) .(\mathrm{pp} .165-186)$. Champaign, IL: Human Kinetics.

Rink, J.E. (2004). It's okay to be a beginner. Journal of Physical Education, Recreation \& Dance, 75(6), 31-34.

Rink, J.E. (2006). Teaching physical education for learning (5th Ed.). Boston: McGraw-Hill.

Rink, J.E., \& Hall, T.J. (2008). Research on effective teaching in elementary school physical education. The Elementary School Journal, 108(3), 207-218.

Roach, K.D. (1997). Effects of graduate teaching assistant attire on student learning, misbehaviors, and ratings of instruction. Communication Quarterly, 45(3), 125-141. 
Rock, I. (1983). The logic of perception. Cambridge, Massachusetts: The MIT Press.

Rookes, P. \& Willson, J. (2000). Perception: Theory, development and organisation. Philadelphia, PA: Routledge.

Underwood, R.A., Kenner, J.O., \& McCune, S. (2002). Principals' perceptions of teaching effectiveness as defined by teachers' dress. Stephen F. Austin State University: Nacogdoches, TX.

Vidourek, R.A., King, K.A., Bernard, A.L., Murnan, J., \& Nabors, L. (2011). Teachers' strategies to positively connect students to school. American Journal of Health Education, 42(2), 116-126.

Vogler, E.W. (2003). Students with disabilities in physical education. In S.J. Silverman, \& C.D. Ennis (Eds.). Student learning in physical education: Applying research to enhance instruction. ( ${ }^{\text {nd }}$ Ed.). (pp. 83-105). Champaign, Illinois: Human Kinetics.

Whitley, J.D., Sage, J.N., \& Butcher, M. (1988). Cardiorespiratory fitness: Role modeling by P.E. instructors. Journal of Physical Education, Recreation \& Dance, 59(7), 81-84.

Workman, J.E., \& Freeburg, B.W. (2009). Dress and Society. New York: Fairchild.

Yilmaz, A. (2011). Quality problem in teaching profession: Qualities teacher candidates feel to be required of teachers. Educational Research and Reviews, 6(14), 812-823. 


\section{APPENDIX A}

\section{Clothing Combinations on the MCAQ}

Mannequin 1: Collared, Long Sleeve Dress Shirt; Tie; Dress Pants; Dress Shoes

Mannequin 2: Collared, Long Sleeve Dress Shirt; Tie; Dress Pants; Running Shoes

Mannequin 3: Short Sleeve Golf Shirt; Dress Pants; Dress Shoes

Mannequin 4: Short Sleeve Golf Shirt; Dress Pants; Running Shoes

Mannequin 5: Long Sleeve Sweat Shirt; Dress Pants; Running Shoes

Mannequin 6: Long Sleeve Sweat Shirt; Dress Pants; Dress Shoes

Mannequin 7: Long Sleeve Shirt; Khaki Pants; Dress Shoes

Mannequin 8: Long Sleeve Shirt; Khaki Pants; Running Shoes

Mannequin 9: Short Sleeve Golf Shirt; Khaki Pants; Dress Shoes

Mannequin 10: Short Sleeve Golf Shirt; Khaki Pants; Running Shoes

Mannequin 11: Long Sleeve Sweat Shirt; Khaki Pants; Running Shoes

Mannequin 12: Long Sleeve Sweat Shirt; Khaki Pants; Dress Shoes

Mannequin 13: Long Sleeve Sweat Shirt; Sweat Pants; Running Shoes

Mannequin 14: Short Sleeve Golf Shirt; Sweat Pants; Running Shoes

Mannequin 15: Short Sleeve Blouse; Skirt; Dress Shoes

Mannequin 16: Short Sleeve Blouse; Skirt; Running Shoes

Mannequin 17: Short Sleeve Golf Shirt; Dress Pants; Running Shoes

Mannequin 18: Short Sleeve Golf Shirt; Dress Pants; Dress Shoes

Mannequin 19: Long Sleeve Sweat Shirt; Dress Pants; Dress Shoes

Mannequin 20: Long Sleeve Sweat Shirt; Dress Pants; Running Shoes

Mannequin 21: Long Sleeve Light Shirt; Khaki Pants; Running Shoes

Mannequin 22: Long Sleeve Light Shirt; Khaki Pants; Dress Shoes

Mannequin 23: Short Sleeve Golf Shirt; Khaki Pants; Dress Shoes

Mannequin 24: Short Sleeve Golf Shirt; Khaki Pants; Running Shoes

Mannequin 25: Long Sleeve Sweat Shirt; Khaki Pants; Dress Shoes

Mannequin 26: Long Sleeve Sweat Shirt; Khaki Pants; Running Shoes

Mannequin 27: Long Sleeve Sweat Shirt; Sweat Pants; Running Shoes

Mannequin 28: Short Sleeve Golf Shirt; Sweat Pants; Running Shoes 